also agree that recording sufficient data during the time constraints of the consultation is a significant challenge. We need to be aware that the average UK primary care consultation with booking intervals of 10 minutes is on the short side for comparable countries and it may be that we need to consider giving ourselves more time.

The problem with the suggestion of typing while we talk (or listen) is that, from a patient's perspective, a doctor who is typing at the same time as they are listening is likely to be perceived as not listening as effectively as a doctor who is simply listening - and in many cases this perception will be correct.

\section{Jonathan Silverman,}

Associate Clinical Dean and Director of Communication Studies, School of Clinical Medicine, University of Cambridge.

E-mail: js355@medschl.cam.ac.uk

\section{Paul Kinnersley,}

Professor, Director of Communication Skills, Department of Primary Care and Public Health, Cardiff University.

\section{REFERENCES}

1. Hay GI. Looking at the patient. Br J Gen Pract 2010; 60(573): 293.

2. Silverman J, Kinnersley P. Look at the patient before you look at the computer. Br J Gen Pract 2010; 60(571): 76-78.

DOI: 10.3399/bjgp10X501921

\section{Aches and pains in primary care}

GPs can do very positive things for some patients with aches and pains as many such patients are Vitamin D deficient. Vitamin D deficiency commonly presents with widespread aches, weakness, and tiredness, and can also present with focal symptoms. If a patient has several musculoskeletal diagnoses over time (for example plantar fasciitis, hip pain, back pain, and knee pain) then Vitamin $D$ deficiency should be suspected.

Deficiency can be confirmed biochemically by checking Vitamin $D$ levels. Expert consensus suggests that optimal Vitamin D status requires serum levels of $25 \mathrm{OH}$ Vitamin D of $75 \mathrm{nmol} / \mathrm{l}$ (that is, $30 \mu \mathrm{g} / \mathrm{l}$ ) or more (repeat levels 3 months after initial treatment to ensure patients are replete). Recent work shows 'no credible evidence' for hypercalcaemia at treatment doses of Vitamin D.'

Treatment must be with adequate doses (for example, 400000 iu in the first 2 weeks and then 20000 weekly) as low dose supplements containing calcium will not restore Vitamin $D$ levels, nor give symptom relief. This condition is common in all ethnic groups, especially in the north and west of the country, and is often forgotten or missed.

I received this comment recently, after treatment (of a white middle-aged man). 'I feel 10 years younger with fewer aches and pains. Mood and energy levels are much improved. I can get about to go fishing much more easily'. Many patients have similar positive experiences.

Moreover, treatment may improve general health as it is now well recognised that Vitamin $\mathrm{D}$ deficiency is a risk factor for many other conditions including cardiovascular disease, diabetes, cancer, and infections. ${ }^{2}$

Finally, patients may approach exercise with more equanimity if the hopeful phrase 'wear and repair' is used instead of the sinister 'wear and tear'.

\section{Avril Danczak,}

GP Tutor/Primary Care Medical

Educator/Trainer, The Alexandra Practice, 365 Wilbraham Road, Manchester, M16 8NG. E-mail: avril.danczak@btinternet.com

\section{REFERENCES}

1. Quinton R, Gan EH, Wahid ST. Hypercalcaemia. Two myths. BMJ 2009: 339: b5649.

2. Pearce SH, Cheetham TD. Diagnosis an management of Vitamin D deficiency. BMJ 2010; 340: b5664.

DOI: 10.3399/bjgp10X501930

\section{Stop and think or think and stop?}

The editorial by Hall et al, ${ }^{1}$ was a brief but fairly comprehensive overview of an area relevant to all GPs. The assessment of whether to continue previously prescribed medication need not, of course, be confined to terminal cancer sufferers. Motor Neurone Disease, endstage organ failure, and advanced dementia are other conditions that spring to mind. My own feeling is that in current practice we probably leave such decisions until they are not decisions at all but rather when swallowing becomes an issue or other problems/side effects occur.

My wry observation is that their own rhetorical question to the title could be misinterpreted. I assume the authors mean it might be time to 'think and stop' rather than the more reactionary converse!

\section{David Carvel,}

Biggar Health Centre, Biggar, Lanarkshire, ML12 6BE. E-mail: carve/@doctors.org.uk

\section{REFERENCE}

1. Hall PS, Lord SR, El-Laboudi, et al. Non-cancer medications for patients with incurable cancer: time to stop and think? Br J Gen Pract 2010; 60(573): 243-244.

DOI: 10.3399/bjgp10X501958

\section{Is stroke a 'trigger'?}

The link between stroke and vascular dementia is known; ${ }^{1}$ reports of psychological disturbance as a direct consequence of brain insult is noted. For example de Groot et $a l,{ }^{2}$ found white matter lesions after depressive episodes in patients with yet more curious phenoma emerging during counselling.

After working at the

Neurorehabilitation Unit, Brighton, it was noted that stroke patients contended with an unusual legacy of past traumas. Disclosed psychological problems originated many years previously: childhood sexual abuse or the re-living of events gave rise to classical posttraumatic stress disorder (PTSD). A 